\title{
LODO TÊXTIL E ÁGUA RESIDUÁRIA DA SUINOCULTURA NA PRODUÇÃO DE MUDAS DE EUCALYPTUS GRANDIS (W, Hill ex Maiden)
}

\section{RODRIGO A. Z. PELISSARI ${ }^{1}$, SÍLVIO C. SAMPAIO², SIMONE D. GOMES ${ }^{3}$, MAURO DA S. CREPALLI ${ }^{4}$}

\begin{abstract}
RESUMO: O objetivo deste trabalho foi avaliar os efeitos do lodo têxtil, adubação e irrigação com água residuária da suinocultura na produção de mudas de Eucalyptus grandis W, Hill ex Maiden. Os tratamentos foram constituídos de três fatores: adubação química $(0 ; 1$ e 2 gramas de NPK 1414-14 por tubete), irrigação (água e água residuária da suinocultura) e substrato com cinco níveis de fracionamento do lodo têxtil e substrato comercial $(0 ; 25 ; 50 ; 75$ e $100 \%)$. Avaliaram-se quatro épocas durante a produção das mudas: germinação. (21 dias), sombreamento (50\%, 40 dias), sombreamento $(18 \%, 20$ dias) e pleno sol (9 dias), com total de 90 dias de produção. As irrigações foram realizadas por aspersão, com lâmina de $12 \mathrm{~mm} \mathrm{dia}^{-1}$. Os parâmetros agronômicos avaliados foram: altura $(\mathrm{H})$, diâmetro (D) e a relação altura/diâmetro (H/D) das plantas. O delineamento experimental usado foi o inteiramente casualizado, em esquema fatorial, com 39 repetições por tratamento. Os resultados obtidos permitiram concluir que o fator adubação química propiciou efeito na altura das plantas, nas últimas épocas de produção das mudas. $\mathrm{O}$ fator substrato apresentou-se de forma negativa quando usado em $100 \%$ do lodo têxtil. A água residuária da suinocultura apresentou os melhores resultados para as mudas, tanto em diâmetro quanto em altura. Utilizando-se do parâmetro da relação altura/diâmetro para a avaliação das mudas, a água residuária da suinocultura propiciou antecipação de 30 dias na produção de mudas de eucalipto.
\end{abstract}

PALAVRAS-CHAVE: reúso de água, resíduos sólidos, aplicação de efluentes.

\section{TEXTILE RESIDUE AND WASTEWATER FROM SWINE CULTURE ON THE EUCALYPTUS PRODUCTION}

\begin{abstract}
The objective of this work was to evaluate the effects of textile silt, seasoning and irrigation with wastewater from swine activities on the production of Eucalyptus seedlings W, Hill ex Maiden. The treatments were constituted by three factors: chemical manuring $(0 ; 1$ and 2 grams of NPK 14-14 by tube), irrigation (water and remaining wastewater from swine) and substratum with five levels of fraction of the textile silt and commercial substratum $(0 ; 25 ; 50 ; 75$ and $100 \%)$. Four periods were evaluated during the production (germination, 21 days), (50\% shadowing, 40 days), (18\% shadowing, 20 days) and (full sun, 9 days) with a total of 90 days of production. The irrigation was performed by aspersion, with $12 \mathrm{~mm} \mathrm{day}^{-1}$. The agronomic parameters evaluated were height $(\mathrm{H})$, diameter (D) and the relation height/diameter $(\mathrm{H} / \mathrm{D})$ of the plants. The experimental delineation used was entirely casual on a factorial scheme with 39 repetitions per treatment. The results obtained allowed to conclude that the chemical season propitiated effect on the plants heights on the last production periods. The substratum factor presented itself on the negative form when used in $100 \%$ of the textile silt. The wastewater from swine culture presented the best results for the samples at diameter and at height. Using the parameter of the Height/Diameter relation to evaluate the samples, the remaining wastewater propitiated an anticipation of 30 days on the eucalyptus production.
\end{abstract}

KEYWORDS: reuse of water, solid residues, effluent.

\footnotetext{
${ }^{1}$ Biólogo, M. Sc. em Engenharia Agrícola, UNIOESTE/RHESA, Rua Universitária, 2069, Cascavel - PR, Fone: (0XX45) 3326 8386, souzapelissari@hotmail.com

${ }^{2}$ Eng $^{\circ}$ Agrícola, Prof. Dr, UNIOESTE/RHESA, Cascavel - PR, ssampaio@ unioeste.br

${ }^{3}$ Eng $^{\mathrm{a}}$ Agrônoma, Profa. Dra., UNIOESTE/RHESA, Cascavel - PR, simoned@ unioeste.br

${ }^{4}$ Biólogo, M. Sc. em Engenharia Agrícola, UNIOESTE/RHESA, Cascavel - PR, mauscrep@ yahoo.com.br.

Recebido pelo Conselho Editorial em: 3-11-2007
}

Aprovado pelo Conselho Editorial em: 26-2-2009

Eng. Agríc., Jaboticabal, v.29, n.2, p.288-300, abr./jun. 2009 


\section{INTRODUÇÃO}

O êxito na formação de florestas de alta produção depende, em grande parte, da qualidade das mudas plantadas que, além de terem de resistir às condições adversas encontradas no campo após o plantio, deverão sobreviver e, por fim, produzir árvores com crescimento volumétrico economicamente desejável (GOMES et al., 1991).

A sobrevivência, o estabelecimento, a frequência dos tratos culturais e o crescimento inicial das florestas são avaliações necessárias para o sucesso do empreendimento florestal, o que está diretamente relacionado com a qualidade das mudas por ocasião do plantio (DURYEA, 1985; GOMES et al., 1991; FONSECA, 2000), merecendo ressaltar que o potencial genético, as condições fitossanitárias e a conformação do sistema radicular são importantes para a boa produtividade dos povoamentos florestais (CARVALHO, 1992).

A necessidade de produzir mudas em áreas bem definidas, com características específicas e controladas, deve-se ao fato de serem geralmente frágeis, precisando de proteção inicial e de manejos especiais, de maneira a obter maior uniformização de crescimento, tal que, após o plantio, permita que resistam às condições adversas encontradas, sobrevivam e depois cresçam satisfatoriamente (GOMES et al., 2002).

O Eucalyptus grandis é a espécie florestal mais plantada no Brasil (SOUZA et al., 2006), devido ao seu potencial produtivo e às características da madeira, sendo utilizada na produção de celulose, de papel, de painéis de fibra e de aglomerados combustíveis industriais e domésticos, e na indústria moveleira (SOARES et al., 2003).

A crescente demanda por melhores condições ambientais tem exigido de empresas públicas e privadas a definição de políticas ambientais mais avançadas, incluindo o tratamento de efluentes. A quantidade de efluentes tratados tende a aumentar, e seu tratamento tem gerado resíduo denominado lodo, que, depois de tratado e higienizado, se torna sólido e é conhecido como biossólido, uma opção de substrato para produtores de mudas florestais (BARREIROS et al., 2007).

A adubação química e/ou orgânica é eficiente em plantações florestais com espécies particularmente do gênero Eucalyptus, e o uso do lodo (biossólidos e efluentes) representa alternativa promissora, como demonstrado em plantações florestais no Brasil e no exterior (HENRY et al., 1994; LIMA, 2005; POGGIANI, 2004).

A utilização de substratos alternativos, como os biossólidos e efluentes líquidos originados do manejo de animais, como da suinocultura, representa a possibilidade de associar ganhos ao silvicultor e produtor, por meio do aumento da produtividade das culturas e redução na utilização de fertilizantes químicos, com ganho aos que produzem esses biossólidos e efluentes, pela efetivação de métodos adequados e mais econômicos de disposição final desse resíduo. Esses adubos orgânicos, além do fornecimento de nutrientes para culturas agronômicas, destacam-se por um papel fundamental e tão importante quanto os nutrientes que são o fornecimento de matéria orgânica para melhorar as propriedades físicas, químicas e biológicas do solo (SOUZA et al, 2006).

\section{MATERIAL E MÉTODOS}

O processo de produção das mudas de Eucalyptus grandis W, Hill ex Maiden foi conduzido no Viveiro Florestal da Mata, de propriedade do Sr. Günther Krüger, BR 277, km 607, Gleba São Francisco, Linha Guavirá, Fazenda Mauá, em Santa Tereza do Oeste - PR.

Os tratamentos foram constituídos a partir de três fatores: adubação química, com três níveis (0; 1 e 2 g por tubete de NPK 14-14-14); irrigação, com dois tipos de água (água e água residuária da suinocultura-ARS), e fator substrato, com cinco níveis de lodo têxtil misturado ao substrato comercial $(0 ; 25 ; 50 ; 75$ e $100 \%)$.

Foi avaliado, também, o fator tempo durante a produção das mudas, pois apresentam-se quatro épocas distintas: germinação, sombrite $50 \%$, sombrite $18 \%$ e pleno sol. Destaca-se que essas 
etapas com sombrite caracterizam a época de aclimatação das mudas para posterior transplantio. Observa-se, na Tabela 1, o resumo dos tratamentos avaliados.

TABELA 1. Tratamentos estudados para irrigação de água e ARS. Treatments studied for water irrigation and wastewater from pig activities.

\begin{tabular}{cccc}
\hline $\mathrm{N}^{\mathrm{o}}$ do Tratamento & Qtde de adubação em $\mathrm{g}^{*}$ & $\begin{array}{c}\text { \% do Resíduo Têxtil/ } \\
\text { Substrato Comercial }\end{array}$ & Irrigação \\
\hline 1 & 0 & 0 & Água/ARS \\
2 & 0 & 25 & Água/ARS \\
3 & 0 & 50 & Água/ARS \\
4 & 0 & 75 & Água/ARS \\
5 & 0 & 100 & Água/ARS \\
6 & 1 & 0 & Água/ARS \\
7 & 1 & 25 & Água/ARS \\
8 & 1 & 50 & Água/ARS \\
9 & 1 & 75 & Água/ARS \\
10 & 1 & 100 & Água/ARS \\
11 & 2 & & \\
12 & 2 & 0 & Água/ARS \\
13 & 2 & 25 & Água/ARS \\
14 & 2 & 50 & Água/ARS \\
15 & 2 & 75 & Água/ARS \\
\hline
\end{tabular}

*A adubação usada em grama é o N-P-K (14-14-14), adubação de base, OSMOCOTE®, adubo de liberação lenta.

Os períodos respectivos a essas épocas foram: 21; 40; 20 e 9 dias, tempos adquiridos a partir de informações do próprio viveiro.

As mudas foram semeadas em tubetes de plástico com volume de $53 \mathrm{~cm}^{3}$, em bandejas de 0,45 m x $1 \mathrm{~m}$, com capacidade de 403 tubetes.

O substrato composto foi obtido utilizando-se de mistura do comercial (Plantmax ${ }^{\circledR}$ ) que foi adquirido no comércio local, formulado a partir de 33\% de casca de Pínus compostadas, 34\% de casca de arroz carbonizadas, $13 \%$ de húmus e $10 \%$ de vermiculita com o incremento de lodo da indústria têxtil, na proporção de $0 ; 25 ; 50 ; 75100 \%$ de lodo têxtil e substrato comercial.

O adubo usado foi o N-P-K (14-14-14) de liberação lenta (OSMOCOTE®), junto ao substrato em cada tubete, na dose de $0 \mathrm{~g}, 1 \mathrm{~g}$ e $2 \mathrm{~g}$ por tubete, dose essa recomendada pelo fabricante, citadas na Tabela 1.

$\mathrm{Na}$ caracterização da água residuária da suinocultura, coletaram-se, aleatoriamente, quatro amostras de 1,5 L nos galões-reservatório. Das amostras, retiraram-se alíquotas de $200 \mathrm{~mL}$, que foram imediatamente acondicionadas em freezer $\left(-4^{\circ} \mathrm{C}\right)$ para posterior análise química. Foram avaliadas as seguintes variáveis: condutividade elétrica (CE), usando-se condutivímetro digital marca Orion, modelo 125; densidade, utilizando-se de densímetro de escala 1,000 a 1,100 (SCHERER, et al., 1995) e sólidos totais (ST) e sedimentáveis (SP) (BRAILE \& CAVALCANTI, 1979). O teor de $\mathrm{N}$-total foi determinado em alíquota de $3,0 \mathrm{~mL}$, pelo método de Kjeldahl (TEDESCO et al., 1985). Alíquotas de 5,0 mL foram mineralizadas via digestão nítrico-perclórica ( $3 \mathrm{~mL}$ de ácido nítrico: $1 \mathrm{~mL}$ de ácido perclórico). Nos extratos de digestão, as concentrações de $\mathrm{Ca}^{2+}, \mathrm{Mg}^{2+}, \mathrm{Cu}^{2+}$ e $\mathrm{Zn}^{2+}$ foram determinadas por espectrofotometria de absorção atômica, e as concentrações de $\mathrm{K}^{+}$e $\mathrm{Na}^{+}$, determinadas por fotometria de emissão de chama, e as do P-total, por colorimetria, pelo método do ácido ascórbico, modificado por BRAGA \& DEFELIPO (1974). Os 
resultados das análises física e química do lodo têxtil utilizado como substrato e da água residuária da suinocultura utilizada na irrigação encontram-se na Tabela 2.

TABELA 2. Caracterização física e química do lodo têxtil usado como substrato e da água residuária da suinocultura usada para irrigação. Physical and chemical characterization of textile sludge used as a substrate and the pig wastewater used for irrigation.

\begin{tabular}{lclr}
\hline \multicolumn{2}{c}{ Composto de Lodo Têxtil } & \multicolumn{2}{c}{ Composto de ARS* } \\
\hline $\mathrm{N}-\mathrm{NO}_{3}\left(\mathrm{~g} \mathrm{~kg}^{-1}\right)$ & 34,36 & $* * \mathrm{CE}\left(\mathrm{dS} \mathrm{m}{ }^{-1}\right)$ & 6,234 \\
$\mathrm{~K}\left(\mathrm{~g} \mathrm{~kg}^{-1}\right)$ & 1,00 & $* *$ Densidade & 1,005 \\
$\mathrm{P}\left(\mathrm{g} \mathrm{kg}^{-1}\right)$ & 3,45 & $* * \mathrm{SP}\left(\mathrm{mL} \mathrm{L}^{-1}\right)$ & 88,250 \\
$\mathrm{Ca}\left(\mathrm{g} \mathrm{kg}^{-1}\right)$ & 3,35 & $* * \mathrm{ST}\left(\mathrm{g} \mathrm{L}^{-1}\right)$ & 5,500 \\
$\mathrm{Mg}\left(\mathrm{g} \mathrm{kg}^{-1}\right)$ & 1,60 & $\mathrm{P}$ total $\left(\mathrm{mg} \mathrm{L}^{-1}\right)$ & 0,0088 \\
$\mathrm{Cu}\left(\mathrm{mg} \mathrm{kg}^{-1}\right)$ & 81,00 & $\mathrm{~N}$ total $\left(\mathrm{mg} \mathrm{L}^{-1}\right)$ & 0,0936 \\
$\mathrm{Zn}\left(\mathrm{mg} \mathrm{kg}^{-1}\right)$ & 159 & $\mathrm{Ca}\left(\mathrm{g} \mathrm{L}^{-1}\right)$ & 0,1300 \\
$\mathrm{Cd}\left(\mathrm{mg} \mathrm{kg}^{-1}\right)$ & - & $\mathrm{Mg}\left(\mathrm{g} \mathrm{L}^{-1}\right)$ & 0,0505 \\
$\mathrm{Cr}\left(\mathrm{mg} \mathrm{kg}^{-1}\right)$ & - & $\mathrm{Na}\left(\mathrm{g} \mathrm{L}^{-1}\right)$ & 0,02047 \\
$\mathrm{Ni}\left(\mathrm{mg} \mathrm{kg}^{-1}\right)$ & - & $\mathrm{K}\left(\mathrm{g} \mathrm{L}^{-1}\right)$ & 0,5049 \\
$\mathrm{~Pb}\left(\mathrm{mg} \mathrm{kg}^{-1}\right)$ & - & $\mathrm{Cu}\left(\mathrm{mg} \mathrm{L}^{-1}\right)$ & 1,6090 \\
$\mathrm{Mo}\left(\mathrm{mg} \mathrm{kg}^{-1}\right)$ & 4,39 & $\mathrm{Zn}\left(\mathrm{mg} \mathrm{L}^{-1}\right)$ & 1,1542 \\
\hline
\end{tabular}

* ARS: água residuária da suinocultura, ${ }^{* *} \mathrm{CE}$ condutividade elétrica; SP. sólidos sedimentáveis, ST; sólidos totais.

As irrigações com água foram realizadas pelo método da aspersão, com lâmina aplicada de $12 \mathrm{~mm} \mathrm{dia}^{-1}$. A irrigação com água residuária da suinocultura (ARS) deu-se de forma manual, com o auxílio de regadores, pois o mesmo se encontrava in natura com concentração elevada de sólidos totais, dificultando a rega por aspersão com a mesma lâmina diária.

Os parâmetros de qualidade agronômica das mudas analisados foram a altura de plantas $(\mathrm{H}) \mathrm{e}$ o diâmetro (D) de caule, visto que essas características indicam boas qualidades agronômicas necessárias para o plantio no campo, segundo WENDLING (2002).

Avaliou-se, também, a relação entre esses parâmetros (H/D) por ser indicativo primordial no replantio das mudas em campo, segundo TRIGUEIRO \& GUERRINI (2003).

O delineamento experimental usado foi o inteiramente casualizado, em esquema fatorial $2 \times 3 \times 5$, com três repetições por tratamento, sendo que cada parcela experimental tinha 13 plantas, sendo que a média dos parâmetros analisados foi usada como medida da parcela. Os fatores avaliados constituíram os tratamentos descritos anteriormente. Ressalta-se, ainda, que se realizaram quatro análises estatísticas respectivas aos tempos de observação. Entretanto, para a primeira época (germinação), na avaliação do diâmetro, não foi possível a realização de leitura em função do pequeno tamanho das mudas.

\section{RESULTADOS E DISCUSSÃO}

\section{Altura da planta}

Observa-se, na Tabela 3, que, na primeira época E1 (germinação), apenas o fator lodo isolado apresentou diferença significativa. Na época E2 (sombrite 50\%), houve interação significativa entre irrigação e lodo. O fator adubação apenas produziu efeitos significativos nas épocas E3 (sombrite 18\%) e época E4 (pleno sol), sendo mantida significância para a interação irrigação com o lodo. 
TABELA 3. Valores de quadrado médio das análises de variância para altura de plantas nas épocas E1 (germinação), E2 (sombrite 50\%), E3 (sombrite 18\%) e E4 (pleno sol). Mean square values of the analyses of variance for height of plants in seasons E1 (germination), E2 (Shadows 50\%), E3 (Shadows 18\%) and E4 (full sun).

\begin{tabular}{ccccc}
\hline FV & E1 & E2 & E3 & E4 \\
\hline IR & 0,729 & 94,905 & $2.153,06$ & $12.198,25$ \\
Erro 1 & 0,673 & 12,581 & 21,682 & 80,668 \\
AD & 0,016 & 0,268 & $\underline{30,100^{*}}$ & $\underline{88,178^{*}}$ \\
L & $\underline{1,046^{*}}$ & 4,390 & 44,156 & 168,448 \\
IR*AD & 0,089 & 0,227 & 0,995 & 26,392 \\
IR*L & 0,119 & $\underline{1,773^{*}}$ & $\underline{29,393 *}$ & $\underline{80,246^{*}}$ \\
AD*L & 0,185 & 0,175 & 2,497 & 7,112 \\
IR*AD*L & 0,156 & 0,642 & 9,730 & 30,928 \\
Erro 2 & 0,156 & 0,664 & 4,682 & 20,390 \\
C.V. 1 $(\%)$ & 29,19 & 58,52 & 23,65 & 23,30 \\
C.V. 2(\%) & 14,06 & 13,45 & 10,99 & 11,72 \\
\hline
\end{tabular}

*teste significativo a 5\% de probabilidade, de acordo com Tukey. IR- irrigação: AD- adubação: L-lodo.

Nota-se que, na Tabela 4, na época da germinação (E1), o maior valor de média da altura das plantas $(2,99 \mathrm{~cm})$ foi encontrado quando se utilizou o substrato com lodo têxtil, a $75 \%$, e o menor valor $(2,39 \mathrm{~cm})$ foi encontrado quando se utilizaram $100 \%$ de lodo têxtil no substrato. Efeitos significativos dos demais fatores não foram observados devido, nessa época, a irrigação ser reduzida em função do encharcamento das sementes, pois podem ocorrer problemas para as mudas e também por se tratar de adubação lenta.

TABELA 4. Valores das médias da altura das plantas para o lodo na época E1. Average plant height values for the sludge in season E1.

\begin{tabular}{cc}
\hline Substrato & Médias \\
\hline $0 \%$ & $2,86 \mathrm{a}$ \\
$25 \%$ & $2,95 \mathrm{a}$ \\
$50 \%$ & $2,85 \mathrm{a}$ \\
$75 \%$ & $2,99 \mathrm{a}$ \\
$100 \%$ & $2,39 \mathrm{~b}$ \\
\hline
\end{tabular}

Letras iguais correspondem a médias iguais a 5\% de significância, de acordo com o teste de Tukey.

Na Tabela 5, é apresentado o desdobramento da interação irrigação com lodo para a época 2 (E2), em que é possível verificar o efeito significativo favorável da água residuária da suinocultura (ARS) quando se avalia apenas a água de irrigação. Entretanto, apenas a ARS propiciou diferença significativa, quando interagiu com o lodo (Tabela 5). Nesse sentido, observa-se que, novamente, o substrato com $25 \%$ de lodo têxtil apresentou maior altura, sendo a menor para $100 \%$ de lodo têxtil. Isso, provavelmente, indica toxicidade de algum composto presente no lodo têxtil nas mudas, quando usado na sua maior concentração.

TABELA 5. Valores das médias de altura das plantas na época E2 para a interação lodo x irrigação. Average plant height values in season $\mathrm{E} 2$ for interaction mud $\mathrm{x}$ irrigation.

\begin{tabular}{cccccc}
\hline Líquido Utilizado na & \multicolumn{5}{c}{ Lodo Presente no Substrato } \\
\cline { 2 - 6 } Irrigação & $0 \%$ & $25 \%$ & $50 \%$ & $75 \%$ & $100 \%$ \\
\hline Água & $4,94 \mathrm{aA}$ & $4,95 \mathrm{aA}$ & $5,04 \mathrm{aA}$ & $5,51 \mathrm{aA}$ & $4,71 \mathrm{aA}$ \\
ARS & $7,37 \mathrm{bA}$ & $7,63 \mathrm{bA}$ & $7,12 \mathrm{bA}$ & $7,56 \mathrm{bA}$ & $5,75 \mathrm{bB}$ \\
\hline
\end{tabular}

Para cada nível de irrigação, letras minúsculas iguais indicam que as médias não diferem entre si, e para cada nível de lodo, letras maiúsculas iguais indicam que as médias não diferem entre si, pelo teste de Tukey, a 5\% de significância. ARS - Água residuária da suinocultura. 
$\mathrm{Na}$ época de sombreamento de $18 \%$ (Tabela 6), a adubação química teve efeito isolado em função de a liberação desse tipo de adubo ser lenta, conforme citado pelo fabricante. O resultado indica que, novamente, existe deficiência de adubação em função da água residuária e do substrato. Essa observação confirma o resultado de WENDLING (2002), que citou que a adubação química com dose de $2 \mathrm{~g}$ por tubete é necessária para substrato de baixa fertilidade.

TABELA 6. Valores das médias de altura das plantas na época E3 para adubação. Average plant height values in season $\mathrm{E3}$ for fertilization.

\begin{tabular}{cl}
\hline Adubação (g de adubo por tubete) & Médias \\
\hline 0 & $18,79 \mathrm{a}$ \\
1 & $19,48 \mathrm{ab}$ \\
2 & $20,77 \mathrm{~b}$ \\
\hline
\end{tabular}

Letras iguais correspondem a médias iguais a 5\% de significância, de acordo com o teste de Tukey.

Na Tabela 7, é apresentado o desdobramento da interação da irrigação com o lodo. Observase que, nessa época, em média, a água residuária da suinocultura ainda produz maiores alturas de plantas em todos os níveis de lodo. Também, é possível notar que a água pura produziu comportamento semelhante à água residuária da suinocultura, entre os níveis do lodo, o que não ocorreu na época anterior.

TABELA 7. Valores das médias de altura das plantas na época E3 para a interação lodo x irrigação. Average plant height values in the season $\mathrm{E3}$ for interaction mud $\mathrm{x}$ irrigation.

\begin{tabular}{cllccc}
\hline Líquido Utilizado na & \multicolumn{5}{c}{ Lodo Presente no Substrato } \\
\cline { 2 - 6 } Irrigação & \multicolumn{1}{c}{$0 \%$} & $25 \%$ & $50 \%$ & $75 \%$ & $100 \%$ \\
\hline Água & $11,49 \mathrm{aA}$ & $13,58 \mathrm{aAB}$ & $15,59 \mathrm{aBC}$ & $17,28 \mathrm{aC}$ & $16,01 \mathrm{aBC}$ \\
ARS & $24,13 \mathrm{bAB}$ & $25,06 \mathrm{bB}$ & $25,08 \mathrm{bB}$ & $26,66 \mathrm{bB}$ & $21,93 \mathrm{bA}$ \\
\hline
\end{tabular}

Para cada nível de irrigação, letras minúsculas iguais indicam que as médias não diferem entre si, e para cada nível de lodo, letras maiúsculas iguais indicam que as médias não diferem entre si, pelo teste de Tukey, a 5\% de significância. ARS - água residuária da suinocultura

Quando as mudas estavam na época de transplantio (E4), os tratamentos proporcionaram comportamentos semelhantes à $3^{\underline{a}}$ época, como pode ser observado nas Tabelas 8 e 9.

TABELA 8. Valores das médias de altura das plantas na época E4 para adubação. Average plant height values in the season $\mathrm{E} 4$ for fertilization.

\begin{tabular}{cl}
\hline Adubação $\left(\mathrm{g} \mathrm{tubete}^{-1}\right)$ & Médias \\
\hline 1 & $37,22 \mathrm{a}$ \\
2 & $37,90 \mathrm{ab}$ \\
3 & $40,48 \mathrm{~b}$ \\
\hline
\end{tabular}

Letras iguais correspondem a médias iguais, a 5\% de significância, de acordo com o teste de Tukey.

$\mathrm{Na}$ Tabela 9, verifica-se, no desdobramento de água residuária com o lodo, que a água residuária ainda proporcionou maiores alturas médias finais que a água. Entretanto, não houve efeito significativo do lodo dentro da água residuária da suinocultura. 
TABELA 9. Valores das médias de altura das plantas na época E4 para a interação lodo com a irrigação. Average plant height values in season $\mathbf{E} 4$ for the interaction with the mud irrigation.

\begin{tabular}{cccccc}
\hline Líquido Utilizado & \multicolumn{5}{c}{ Lodo Presente no Substrato } \\
\cline { 2 - 5 } na Irrigação & $0 \%$ & $25 \%$ & $50 \%$ & $75 \%$ & $100 \%$ \\
\hline Água & $18,86 \mathrm{aA}$ & $25,14 \mathrm{aB}$ & $28,16 \mathrm{aBC}$ & $31,90 \mathrm{aC}$ & $30,38 \mathrm{aBC}$ \\
ARS & $48,87 \mathrm{bA}$ & $49,33 \mathrm{bA}$ & $51,02 \mathrm{bA}$ & $51,46 \mathrm{bA}$ & $50,22 \mathrm{bA}$ \\
\hline
\end{tabular}

Para cada nível de irrigação, letras minúsculas iguais indicam que as médias não diferem entre si, e para cada nível de lodo, letras maiúsculas iguais indicam que as médias não diferem entre si, pelo teste de Tukey, a 5\% de significância. ARS - Água residuária da suinocultura.

\section{Diâmetro das plantas}

Na Tabela 10, encontram-se os resultados das análises de variância de todas as médias dos 30 tratamentos para o diâmetro das plantas para as quatro épocas avaliadas.

TABELA 10. Valores de quadrado médio das análises de variância para diâmetro de plantas nas épocas de E1 (germinação), E2 (sombrite 50\%), E3 (sombrite 18\%) e E4 (pleno sol). Mean square values of the analyses of variance for diameter of plants in times of E1 (germination), E2 (Shadows 50\%), E3 (Shadows 18\%) and E4 (full sun).

\begin{tabular}{cccc}
\hline FV & T2 & T3 & T4 \\
\hline IR & 2,212 & 2,659 & $\underline{3,864^{* *}}$ \\
Erro 1 & 0,010 & 1,368 & 0,646 \\
AD & 0,005 & 0,029 & 0,015 \\
L & 0,041 & $\underline{0,083 *}$ & 0,037 \\
IR*AD & 0,002 & 0,049 & 0,046 \\
IR*L & $\underline{0,039 *}$ & 0,005 & 0,021 \\
AD*L & 0,012 & 0,011 & 0,007 \\
IR*AD*L & 0,006 & 0,005 & 0,021 \\
Erro 2 & 0,010 & 0,022 & 0,026 \\
C.V.1 $(\%)$ & 10,66 & 75,53 & 31,95 \\
C.V.2(\%) & 10,66 & 9,60 & 6,51 \\
\hline
\end{tabular}

** teste significativo a 7\% de probabilidade, de acordo com Tukey. IR- Irrigação, AD- Adubação, L- Lodo.

Observa-se, nessa Tabela 10, que houve efeito significativo para os fatores irrigação com o lodo, lodo isolado e irrigação isolada, nas épocas E2, E3 e E4, respectivamente.

Nas Tabelas 11; 12 e 13, são apresentados o desdobramento e os efeitos isolados dos parâmetros água residuária da suinocultura, adubação e irrigação para as épocas E2, E3 e E4.

TABELA 11. Valores das médias do diâmetro das plantas na época E2 para a interação lodo $\mathrm{x}$ irrigação. Average plant diameter values in season $E 2$ for interaction mud $x$ irrigation.

\begin{tabular}{cccccc}
\hline Líquido Utilizado & \multicolumn{5}{c}{ Lodo Presente no Substrato } \\
\cline { 2 - 6 } na Irrigação & $0 \%$ & $25 \%$ & $50 \%$ & $75 \%$ & $100 \%$ \\
\hline Água & $0,79 \mathrm{aA}$ & $0,78 \mathrm{aA}$ & $0,81 \mathrm{Aa}$ & $0,89 \mathrm{aA}$ & $0,81 \mathrm{aA}$ \\
ARS & $1,18 \mathrm{bA}$ & $1,19 \mathrm{bA}$ & $1,1 \mathrm{bAB}$ & $1,18 \mathrm{bA}$ & $0,99 \mathrm{bB}$ \\
\hline
\end{tabular}

Para cada de nível de irrigação, letras minúsculas iguais indicam que as médias não diferem entre si, e para cada nível de lodo, letras maiúsculas iguais indicam que as médias não diferem entre si, pelo teste de Tukey, a 5\% de significância. ARS - Água residuária da suinocultura.

Percebe-se, nas épocas E2 e E3, que o lodo apresentou efeito negativo no desenvolvimento do diâmetro das plantas, semelhante ao ocorrido nas épocas iniciais para altura das plantas. A água 
residuária propiciou efeito positivo significativo apenas na época E4, ou seja, ao final da produção da muda.

TABELA 12. Valores das médias de diâmetro das plantas para o lodo na época E3. Average plant diameter values for the sludge at the season $E 3$.

\begin{tabular}{cc}
\hline Substrato & Médias \\
\hline $0 \%$ & $1,58 \mathrm{a}$ \\
$25 \%$ & $1,60 \mathrm{a}$ \\
$50 \%$ & $1,52 \mathrm{ab}$ \\
$75 \%$ & $1,57 \mathrm{ab}$ \\
$100 \%$ & $1,43 \mathrm{~b}$ \\
\hline
\end{tabular}

Letras iguais correspondem a médias iguais a 5\% de significância, de acordo com o teste de Tukey.

Observa-se, nas Tabelas 11 e 13, o efeito positivo da água residuária da suinocultura no desenvolvimento do diâmetro das plantas, seguindo os resultados da altura das plantas.

TABELA 13. Valores das médias em diâmetro das plantas para a irrigação na época E4. Average plant diameter values for irrigation in season $\mathbf{E 4}$.

\begin{tabular}{cc}
\hline Irrigação & Médias \\
\hline Água & $2,30 \mathrm{a}$ \\
ARS & $2,72 \mathrm{a}$ \\
\hline
\end{tabular}

Letras iguais correspondem a médias iguais a 5\% de significância, de acordo com o teste de Tukey.

ARS - água residuária da suinocultura.

WENDLING (2002) também observou essa tendência, quando cita que a adubação química com dose de 2 g por tubete é necessária para substrato de baixa fertilidade. Também SOUZA et al. (2006) observaram que, em algumas espécies de Eucalyptus (Eucalyptus urophylla), há necessidade de aporte de adubação nitrogenada, mesmo utilizando adubação orgânica de alta fertilidade.

VIEIRA et al. (2004), SILVA et al. (2003) e FAUSTINO et al. (2005), em seus estudos, observaram a possibilidade de bons resultados na associação de lodo com adubações químicas.

De modo geral, observa-se, para altura e diâmetro, o efeito negativo para a concentração de $100 \%$ de lodo têxtil no substrato, nas épocas iniciais. Destaca-se que o nível de $75 \%$ de lodo têxtil tende a ser a dosagem de maior altura e diâmetro para as épocas E3 e E4, principalmente.

HARRISON et al. (2003) conseguiram resultado semelhante, quando estudaram a reciclagem de resíduos sólidos industriais e urbanos em reflorestamento e concluíram que esses tipos de resíduos aplicados em doses acima de $29 \mathrm{~g} \mathrm{~L}^{-1}$ podem fornecer maior resposta no crescimento e mais duradoura que a adubação química.

Vários outros autores verificaram efeitos do lodo têxtil na produção de algumas culturas. PRADO \& NATALLE (2005) notaram que algumas doses de lodo têxtil em substrato causam efeitos positivos na produção de mudas do maracujazeiro. Entretanto, ARAÚJO, MONTEIRO \& CARDOSO (2005) sempre ressaltaram o efeito negativo do lodo têxtil no crescimento de plântulas de soja e de trigo.

VIEIRA et al. (2004), em seu trabalho com fracionamento do lodo de esgoto+adubação nitrogenada, aplicada em trabalho com feijoeiro, afirmaram que a mesma pode ser substituída por lodo de esgoto. SILVA et al. (2003) e FAUSTINO et al. (2005), em seus trabalhos com a variedade IPA 467-42 de nabo forrageiro e Senna siamea Lam, no uso de lodo e lodo+adubação química, relataram que o lodo da indústria têxtil mostrou potencial promissor de uso como fertilizante agrícola. 
Segundo BARREIROS et al. (2007), o decréscimo de densidade da madeira de Eucalyptus Grandis pela adubação com lodo industrial foi compensado pela maior altura das plantas.

Também, de modo geral, observa-se o efeito do tipo de água utilizada na irrigação nos valores de altura e diâmetro das mudas ao longo do período do experimento. Verifica-se, facilmente, que, dentre os fatores avaliados a respeito da influência da água residuária da suinocultura, há maiores efeitos no desenvolvimento das plantas, principalmente na altura das mesmas.

Essa observação demonstra que a variável altura da planta pode ser utilizada de modo único para estimar a qualidade das mudas, de fácil obtenção e por não ser um método definitivo, segundo conclusão de GOMES et al. (2003). TRIGUEIRO \& GUERRINI (2003) notaram, também, que a altura apresentou resultados mais expressivos do que o diâmetro ao final da produção de mudas de Eucalyptus com biossólidos, apesar de DANIEL et al. (1997) e CARNEIRO (1995) indicarem o diâmetro como sendo o parâmetro mais apropriado para avaliar a capacidade de sobrevivência da muda a campo.

Os resultados de HEATON et al. (2002) foram semelhantes aos resultados apresentados pela água residuária da suinocultura no desenvolvimento das mudas, pois observaram, de modo geral, sempre crescimento proporcional linear de raízes de Eucalyptus com a taxa de aplicação de água residuária da bovinocultura tratada em lagoa de estabilização.

Efeitos significativos de água residuária oriunda da produção de animais, principalmente da suinocultura, também são ressaltados em outras culturas com os trabalhos de BEZERRA et al. (2005) e FILHO et al. (2005), que estudaram no cultivo do algodão, e FREITAS et al. (2004), que estudaram no cultivo do milho.

Neste trabalho, o efeito significativo da água residuária da suinocultura, na altura e no diâmetro das plantas, deveu-se, provavelmente, aos altos teores de nitrogênio e fósforo presentes, conforme afirmaram TRIGUEIRO \& GUERRINI (2003), NOVAIS et al. (1980) e NOVAIS et al. (1982), pois o nitrogênio e o fósforo são nutrientes essenciais para a produção de eucalipto.

\section{Relação altura/diâmetro (HD) das plantas}

Observa-se, na Tabela 14, que houve efeito significativo para os fatores lodo isolado na época E2 (sombrite 50\%) e na interação irrigação com a adubação e interação irrigação com o lodo, nas épocas E3 e E 4 (sombrite 18\% e pleno sol), para a relação altura e diâmetro (H/D).

TABELA 14. Valores de quadrado médio das análises de variância da relação altura/diâmetro das plantas nas épocas E2 (sombrite 50\%), E3 (sombrite 18\%) e E4 (pleno sol). Mean square values of the analyses of variance of the relationship height / diameter of the plants for seasons E2 (Shadows 50\%), E3 (Shadows 18\%) and E4 (full sun).

\begin{tabular}{cccc}
\hline FV & E2 & E3 & E4 \\
\hline IR & 0,881 & 151,879 & 996,451 \\
Erro 1 & 7,275 & 109,132 & 10,772 \\
AD & 0,027 & 31,250 & 20,913 \\
L & $\underline{0,889 * *}$ & 26,867 & 37,944 \\
IR*AD & 0,023 & $\underline{11,399^{*}}$ & $\underline{11,007 *}$ \\
IR*L & 0,050 & $\underline{13,934^{*}}$ & $16,285^{*}$ \\
AD*L & 0,207 & 1,777 & 6,514 \\
IR*AD*L & 0,264 & 5,633 & 3,431 \\
Erro 2 & 0,361 & 3,504 & 21,67 \\
C.V.1(\%) & 43,47 & 80,33 & 12,23 \\
C.V.2(\%) & 9,69 & 14,40 & \\
\hline
\end{tabular}

*Significativo a $5 \%$ de probabilidade, pelo teste de Tukey. ** Significativo a 6\%, pelo teste de Tukey. 
$\mathrm{Na}$ Tabela 15, é apresentado o teste de médias para o fator substrato. Observa-se que o nível de $100 \%$ apresentou média diferente estatisticamente dos níveis $0 ; 25 ; 50$ e 75\%, porém todas ficaram dentro de faixa de relação descrita como ideal, segundo TRIGUEIRO \& GUERRINI (2003), que citaram que a faixa de relação entre altura e diâmetro ideal na produção de Eucalyptus deve estar entre 5,4 e 8,1. Os resultados obtidos pelos autores alcançaram médias acima do valor ideal, quando usados substratos fracionados com solo e lodo de esgoto, e substratos comerciais (testemunhas). Os valores variaram entre 10,74 e 12,81 de H/D, em 120 dias de experimento.

TABELA 15. Teste de médias para níveis de lodo têxtil na relação altura/diâmetro das plantas. Test averages for levels of textile sludge in the relationship height/diameter of the plants.

\begin{tabular}{cc}
\hline Substrato & Médias \\
\hline $100 \%$ & $5,81 \mathrm{a}$ \\
$0 \%$ & $6,25 \mathrm{~b}$ \\
$75 \%$ & $6,27 \mathrm{~b}$ \\
$50 \%$ & $6,32 \mathrm{~b}$ \\
$25 \%$ & $6,35 \mathrm{~b}$ \\
\hline
\end{tabular}

Médias seguidas da mesma letra não diferem entre si, a 5\% de significância.

Em 90 dias de experimento, as maiores médias encontradas, analisando-se a irrigação, foram sempre na irrigação com água residuária da suinocultura, nas épocas E3 e E4 (Tabelas 16 e 17).

A adubação de $2 \mathrm{~g}$ por tubete foi a que alcançou as maiores médias nas épocas E3 e E4, ficando em 18,85 de H/D, na época de pleno sol.

TABELA 16. Desdobramento das interações irrigação $\mathrm{x}$ adubação e irrigação $\mathrm{x}$ lodo, na época E3 (sombrite $18 \%$ ) na relação altura/diâmetro. Widening of interactions irrigation $\mathbf{x}$ fertilization and irrigation $x$ mud at the season $E 3$ (Shadows 18\%) in the relation height/diameter.

\begin{tabular}{cccccc}
\hline \multicolumn{5}{c}{ Irrigação x Adubação } \\
\hline \multirow{2}{*}{ Irrigação } & $\begin{array}{c}0 \text { g de adubo } \\
\text { por tubete }\end{array}$ & \multicolumn{2}{c}{$1 \mathrm{~g}$ de adubo por tubete } & 2 g de adubo por tubete \\
\hline Água & $9,92 \mathrm{aA}$ & \multicolumn{2}{c}{$12,07 \mathrm{aB}$} & $13,11 \mathrm{aB}$ \\
ARS & $13,91 \mathrm{bA}$ & \multicolumn{7}{c}{$14,21 \mathrm{bA}$} & $14,78 \mathrm{bA}$ \\
\hline \multicolumn{7}{c}{ Irrigação x Lodo } \\
\hline Irrigação & $0 \%$ de lodo & $25 \%$ de lodo & $50 \%$ de lodo & $75 \%$ de lodo & $100 \%$ de lodo \\
\hline Água & $8,64 \mathrm{aA}$ & $10,72 \mathrm{aAB}$ & $12,29 \mathrm{aBC}$ & $13,30 \mathrm{aC}$ & $13,56 \mathrm{aC}$ \\
ARS & $13,71 \mathrm{bA}$ & $14,00 \mathrm{bA}$ & $14,81 \mathrm{bA}$ & $15,08 \mathrm{bA}$ & $13,89 \mathrm{aA}$ \\
\hline
\end{tabular}

Médias seguidas da mesma letra não diferem entre si, a 5\% de significância. ARS Água residuária da suinocultura.

O lodo têxtil, na época E3, alcançou a maior média, quando usado a 75\%, conforme Tabela 16; porém, na época E4, a maior média foi encontrada para $100 \%$ de lodo têxtil (Tabela 17), resultado esse inverso às épocas E2 e E3. As médias mostraram, nas épocas E2 e E3 que, com o aumento da concentração do lodo têxtil, houve decréscimo da relação altura/diâmetro das plantas.

Observa-se, nos resultados, que a água residuária da suinocultura reduziu o tempo de produção de mudas de Eucalyptus em 30 dias e também a possibilidade de substituição do adubo químico por esse efluente. Portanto, esse fato propicia economia relevante nesse sistema de produção econômica, como, por exemplo, na mão de obra e tempo de acomodação em viveiro, entre outros fatores, como pode ser notado na planilha de contas do viveiro para 90 dias. 
TABELA 17. Desdobramento das interações irrigação x adubação e irrigação x lodo, na época E4 (pleno sol), na relação altura/diâmetro. Widening of interactions irrigation $\mathbf{x}$ fertilization and irrigation $x$ mud at the season $E 4$ (full sun) in the relation height/diameter.

\begin{tabular}{|c|c|c|c|c|c|}
\hline \multicolumn{6}{|c|}{ Irrigação x Adubação } \\
\hline Irrigação & $\begin{array}{l}0 \mathrm{~g} \text { de adubo } \\
\text { por tubete }\end{array}$ & \multicolumn{2}{|c|}{$1 \mathrm{~g}$ de adubo por tubete } & \multicolumn{2}{|c|}{$2 \mathrm{~g}$ de adubo por tubete } \\
\hline Água & $10,47 \mathrm{aA}$ & \multicolumn{2}{|c|}{$11,69 \mathrm{aAB}$} & \multicolumn{2}{|c|}{$13,28 \mathrm{aB}$} \\
\hline ARS & $18,43 \mathrm{bA}$ & \multicolumn{2}{|c|}{$18,12 \mathrm{bA}$} & \multicolumn{2}{|c|}{$18,85 \mathrm{bA}$} \\
\hline \multicolumn{6}{|c|}{ Irrigação x Lodo } \\
\hline Irrigação & $0 \%$ de lodo & $25 \%$ de lodo & $50 \%$ de lodo & $75 \%$ de lodo & $100 \%$ de lodo \\
\hline Água & $8,09 \mathrm{aA}$ & $11,13 \mathrm{aB}$ & $12,35 \mathrm{aBC}$ & $14,09 \mathrm{aC}$ & $13,42 \mathrm{aBC}$ \\
\hline ARS & $17,85 \mathrm{bA}$ & $17,69 \mathrm{bA}$ & $18,85 \mathrm{bA}$ & $18,71 \mathrm{bA}$ & $19,24 \mathrm{bA}$ \\
\hline
\end{tabular}

Médias seguidas da mesma letra não diferem entre si, a 5\% de significância.

\section{CONCLUSÕES}

O fator adubação química propiciou pequeno efeito na altura das plantas e ao final do processo de produção das mudas.

O fator substrato apresentou-se como fator negativo na altura das plantas, em $100 \%$ de lodo têxtil. A concentração de $75 \%$ de lodo têxtil no substrato mostrou a melhor resposta na altura das plantas.

O fator água de irrigação apontou que a água residuária da suinocultura produziu os maiores efeitos positivos para diâmetro e, principalmente, para altura de plantas.

O parâmetro altura de plantas foi o que melhor exibiu resposta frente aos tratamentos.

A água residuária da suinocultura (ARS) propiciou resultados na relação altura/diâmetro que podem antecipar a produção de mudas de Eucalyptus de 90 dias para 60 dias, aproximadamente.

\section{AGRADECIMENTOS}

À Universidade Estadual do Oeste do Paraná (UNIOESTE).

\section{REFERÊNCIAS}

ARAÚJO, A.S.F.; MONTEIRO, R.T.R.; CARDOSO, P. F. Composto de lodo têxtil em plântulas de soja e trigo. Pesquisa Agropecuária Brasileira, Brasília, v.40, n.6, p.549-554, 2005.

BARREIROS, R.M.; GONÇALVES, J.L.M.; SANSÍGOLO, C.A.; POGGIANI, F. Modificações na produtividade e nas características físicas e químicas da madeira de Eucalyptus grandis causadas pela adubação com lodo de esgoto tratado. Revista Árvore, Viçosa, v.31, n.1, p.103-111, 2007.

BRAGA, J.M.; DEFELIPO, B.V. Determinação espectrofotométrica de fósforo em extratos de solo e material vegetal. Revista Ceres, Viçosa, v.21, n.1, p.73-85, 1974.

BRAILE, P.M.; CAVALCANTI, J.E.W.A. Manual de tratamento de águas residuárias industriais. São Paulo: CETESB, 1979. 764 p.

BEZERRA, L.J.D.; LIMA, V.L.A.; ANDRADE, A.R.S.; ALVES, V.W.; AZEVEDO, C.A.V.; GUERRA, H.O.C. Análise de crescimento do algodão colorido sob os efeitos da aplicação de água residuária e biossólidos. Revista Brasileira de Engenharia Agrícola e Ambiental, Campina Grande, v.9, p,333-338, 2005. Suplemento 
CARNEIRO, J.G.A. Produção e controle de qualidade de mudas florestais. Curitiba: Universidade Federal do Paraná, Campos dos Goitacazes: Universidade Estadual do Norte Fluminense, 1995. $451 \mathrm{p}$.

CARVALHO, C.M. Produção de mudas de espécies florestais de rápido crescimento. In: NOVAES, A.B. et al. Reflorestamento no Brasil. Vitória da Conquista: UESB, 1992. p.93-103.

DANIEL, O.; VITORINO, A.C.T.; ALOVISI, A.A.; MAZZOCHIN, L.; TOKURA, A.M. ; PINHEIRO, E.R.; SOUZA, E.F. Aplicação de fósforo em mudas de Acácia mangium Willd, Revista Árvore, Viçosa, v.21, n.2, p.163-168, 1997.

DURYEA, M.L. Evaluating seediing quality importance to reflorestation. In: DURYEA, M.L. Evaluating seedling quality principles. Procedures and predictive abilites of major test. Corvallis: Forest Research Laboratory Oregon State Univerity, 1985. p.1-6.

FAUSTINO, R.; KATO, M. T.; FLORÊNCIO, L.; GAVAZZA, S. Lodo de esgoto como substrato para produção de mudas de Senna siamea Lam. Revista Brasileira de Engenharia Agrícola e Ambiental, Campina Grande, v.9, p.278-282, 2005. Suplemento

FILHO, J.F.; NÓBREGA, J.Q.; SOUSA, J.T.; DANTAS, J.P. Comparação dos efeitos de água residuária e de poço no crescimento e desenvolvimento do algodoeiro. Revista Brasileira de Engenharia Agrícola e Ambiental, Campina Grande, v.9, p.328-332, 2005. Suplemento

FONSECA, R.P. Padrão de qualidade de mudas de Trema mícantha (L.) Blume., Cedrela fissilis Vell., e Aspidosperma polyneuron Mull. Arg., produzidas sob diferentes períodos de sombreamento. Jaboticabal: FCAV, Universidade Estadual Paulista, 2000.

FREITAS, W.S.; OLIVEIRA, R.A.; PINTO, F.A.; CECON, P.R.; GALVÃO, J.C.C. Efeito da aplicação de águas residuárias de suinocultura sobre a produção do milho silagem. Revista Brasileira de Engenharia Agrícola e Ambiental, Campina Grande, v.8, n.1, p.120-125, 2004.

GOMES, J.M.; COUTO, L.; LEITE, H.G.; XAVIER, A.; GARCIA, S.L.R. Crescimento de mudas de Eucalyptus grandis em diferentes tamanhos de tubetes e fertilização N-P-K. Revista Árvore, Viçosa, n.2, p.113-127, 2003.

GOMES, J.M.; COUTO, L.; LEITE, H.G.; XAVIER, A.; GARCIA, S.L.R. Efeito de diferentes substratos na produção de mudas de Eucalyptus grandis W. Hillex Maidem, em "Win-Strip". Revista Árvore, Viçosa, v.5, n.1, p.35-42, 1991.

GOMES, J.M.; COUTO, L.; LEITE, H.G.; XAVIER, A.; GARCIA, S.L.R. Parâmetros morfológicos na avaliação da qualidade de mudas de Eucaliptus grandis. Revista Árvore, Viçosa, v.26, n.6, p.655-664, 2002.

HARRISON, R.B.; GUERRINI, I.A.; HENRY, C.L.; COLE, D.W. Reciclagem de resíduos industriais e urbanos em áreas de reflorestamento. Circular Técnica IPEF, Piracicaba, n.198, p.120, jun. 2003.

HEATON, R.J.; SIMS, R.E.H.; TUNGCUL, R.O. The root growth of salix viminalis and Eucalyptus nitens in response to diry farm pond effluent irrigation. Bioresource Technology, Kidlington, v.81, n.1, p.1-6, 2002.

HENRY, C.L.; COLE, D.W.; HARRISON, R.B. Use of municipal sludge to restore and improve site productivity in forestry: the Pack Forest Sludge Research Program. Forest Ecology and Management, Amsterdam, v.66, p.137-149, 1994.

LIMA, I.L. Influência do desbaste e da adubação na qualidade da madeira de Eucalyptus grandis Hill ex Maidem. 2005. 137 f. Tese (Doutorado em Recursos Florestais) - Escola Superior de Agricultura "Luiz de Queiroz", Universidade de São Paulo, Piracicaba, 2005.

NOVAIS, R,F.; BARROS, N.F.; NEVES, J.C.; COUTO, C. Níveis críticos de fósforo no solo para eucalipto. Revista Árvore, Viçosa, v.6, n.1, p.29-37, 1982. 
NOVAIS, R.F.; RÊGO, A.K,; GOMES, J.M. Nível crítico de potássio no solo e na planta para crescimento de mudas de Eucalyptus grandis W, Hill ex Maiden e de Eucalyptus cloeziana F, Muell, Revista Árvore, Viçosa, v.4, n.1, p.14-23, 1980.

POGGIANI, F. Características do sistema radicular das árvores de Eucalyptus grandis em resposta à aplicação de doses crescentes de biossólido. Scientia Florestalis, Piracicaba, v.65, p.207-218, 2004.

PRADO, R.M.; NATALE, W. Desenvolvimento inicial e estado nutricional do maracujazeiro em resposta a aplicação de lodo têxtil. Pesquisa Agropecuária Brasileira, Brasília, v.40, n.6, p.621626, 2005.

SCHERER, E.E.; BALDISSERA, I.T; DIAS, L.F.X. Método rápido para determinação da qualidade fertilizante do esterco líquido de suíno a campo. Agropecuária Catarinense, Florianópolis, v.8, n.2, p.40-43, 1995.

SILVA, E.P.; MOTA, S.; AQUINO, B. F. Potential of the use of slude from textile industry wwtp as agricultural fertilizer. Engenharia Sanitária e Ambiental, Rio de Janeiro, v.8, n.1, p.69-76, 2003.

SOARES, M.T.S. Taxas de mineralização e de lixiviação do nitrogênio e alterações da fertilidade de um Latossolo Vermelho-Amarelo degradado e outro não degradado fertilizados com biossólidos e florestados com Eucalyptus grandis. 2003. 132 f. Tese (Doutorado em Solos e Nutrição de Plantas) - Escola Superior de Agricultura "Luiz de Queiroz", Universidade de São Paulo, Piracicaba, 2003.

SOUZA, C.A.M.; OLIVEIRA, R.B.; FILHO, S.M.; SOUZA, J.L.S. Crescimento em campo de espécies florestais em diferentes condições de adubação. Ciência Florestal, Santa Maria, v.16, n.3, p.243-249, 2006.

TEDESCO, J.M.; VOLKWEISS, S.J.; BOHNEN, H. Análises de solo, plantas e outros materiais. Porto Alegre: UFRGS, 1985. 186 p.

TRIGUEIRO, R.M.; GUERRINI, I.A. Uso de biossólido como substrato para produção de mudas de eucalipto. Sciencia Florestalis, Piracicaba, v.64, p.150-162, dez. 2003.

VIEIRA, R.F.; TSAI, S.M.; TEIXEIRA, M.A. Efeito de lodo de esgoto no crescimento e fixação simbiótica do $\mathrm{N}_{2}$ em feijoeiro (Phaseolus vulgaris L.). Jaguariúna: Embrapa Meio Ambiente, 2004. $18 \mathrm{p}$.

WENDLING, I. Curso intensivo de viveiros e produção de mudas. In: WENDLING, I.; FERRARI, M.P.; GROSSI, F. Colombo: Embrapa Florestas, 2002, 48 p. (Documentos, 79). 